\title{
Caracterización histórica y socioeconómica de una franja territorial yuquera en el distrito de La Fortuna, San Carlos y Peñas Blancas, San Ramón, región Huetar Norte de Costa Rica
}

Historical and socio-economic characterization of a territorial strip of cassava growing in the district of La Fortuna, San Carlos and Peñas Blancas, San Ramon, North Huétar region of Costa Rica

Francisco Rodríguez-Barrientos' Óscar Córdoba-Artavia² 


\section{Palabras clave}

Franja territorial yuquera; La Fortuna, San Carlos; Peñas Blancas de San Ramón; Región Huetar Norte; nueva agroexportación; consecuencias sociales y económicas de la nueva agroexportación.

\section{Resumen}

El presente artículo se deriva del proyecto de investigación "Mejora en la eficiencia de la cadena productiva de la yuca en el distrito de La Fortuna, San Carlos, Costa Rica". Su objetivo fundamental consistía en mejorar la eficiencia y la productividad en las diversas etapas del proceso agroproductivo de la yuca. La investigación se realizó en una franja territorial que abarcó un sector del distrito de La Fortuna, cantón de San Carlos, provincia de Alajuela, Costa Rica, tradicionalmente un importante lugar de producción yuquera, y otro del distrito de Peñas Blancas (cantón de San Ramón, provincia de Alajuela). Esa franja territorial es parte de la Región Huetar Norte costarricense y su sector ligado a la producción, procesamiento y comercialización de yuca constituyó la población meta de la investigación. El proyecto tuvo una duración de tres años (2006-2008).

En este artículo se hace una caracterización histórica, social y económica de dicha franja territorial. Además, se analizan las consecuencias económicas y sociales, tanto para las comunidades ubicadas en la franja territorial estudiada como para la región de la que forman parte, derivadas de los cambios ocurridos en los ámbitos nacional e internacional, sobre todo en los últimos treinta años. De este modo, se intenta perfilar el alcance y la índole de las eventuales transformaciones acaecidas en la franja seleccionada, ubicando siempre el análisis en el contexto de la región Huetar Norte. Posteriormente se publicarán más artículos con los resultados obtenidos en las etapas agrícola, industrial (maquiladoras y empacadoras) y social, destacando lo relacionado con la situación de los trabajadores en las empacadoras, haciendo énfasis en los migrantes nicaragüenses.

\section{Key words}

Cassava strip of land; La Fortuna, San Carlos; Peñas Blancas de San Ramón; Región Huetar Norte; new agroexportation; social and economic consequences of the new agroexportation.

\section{Abstract}

This article derives from the research project "Improvement in the efficiency of the productive chain of cassava in the district of Fortune, San Carlos, Costa Rica." The main objective of the project consisted on improving the efficiency and productivity in the various stages of the agro productive process of the cassava. The research was conducted in a strip of land covering an area of the district of La Fortuna, canton of San Carlos, Alajuela, Costa Rica, traditionally a major cassava growing production site, and an area of the district of Peñas Blancas (canton of San Ramón, Alajuela province). The strip of land selected is within the North Huetar Costa Rica. This population, connected to the production sector, processing and marketing of cassava, was the goal of the research population. The project lasted three years (2006-2008).

This article makes a historical, social and economic characterization of the strip of land chosen for the research. However, the article also analyzes the economic and social consequences for the communities located in the territory studied, and the region of which they form part, derived from the national and international changes occurred, especially, in the last thirty years. Thus, we try to outline the scope and nature of any transformations in the selected band, always placing the analysis within the context of North Huetar. Subsequently articles will be published with the results obtained in the agricultural industries (maquiladoras and packing) an social stages, highlighting those matters related to the situation of workers in packing, emphasizing on the Nicaraguan migrants. 


\section{Introducción}

El cultivo de la yuca es una actividad agrícola de gran importancia en Costa Rica, tanto para el mercado interno como internacional. El consumo nacional se estima entre 12000 y 18000 toneladas (Fonseca y Saborío, 200I) y la exportación de productos frescos y parafinados alcanzó en 2006 un total de 45,981 toneladas, aumentando en 2008 a 75000 toneladas y en 2009 a 82000 toneladas. Estados Unidos es el principal mercado internacional de Costa Rica (Barquero, 20I0), con el 90\% del total de las exportaciones costarricenses de yuca. A principios del siglo actual, el 95\% de las importaciones de yuca norteamericanas provenían de Costa Rica, aunque en años posteriores países como Ecuador han venido ganado porciones de ese importante mercado (Fonseca y Saborío, 200 I).

Las pérdidas poscosecha de yuca son de un 30\% a 35\%, alcanzando en algunos casos hasta 55\% el porcentaje de rechazo de una yuca parafinada de exportación. Cerca de 20\% a 25\% de la yuca se comercializa sin cumplir con las características idóneas para tal propósito, lo que ha provocado una reducción del volumen ofertado, por lo tanto se deteriora la imagen y la calidad de la yuca que Costa Rica produce y exporta (Fonseca y Saborío, 200I).

La yuca también tiene otro inconveniente: la constante baja de los precios en el mercado internacional que suele afectar sobre todo a los pequeños y medianos productores. La sobreoferta es la causa principal de la baja en los precios. Este hecho explica que Costa Rica recibiera US\$64 millones por las 75000 toneladas exportadas en 2008 pero solo US\$47 millones en 2009, a pesar de haber exportado una mayor cantidad de yuca: 82000 toneladas.

El cantón de San Carlos ha sido tradicionalmente un importante productor de yuca. Hasta 1980 la mayor parte de la producción se colocaba en el mercado nacional, pero con la estrategia neoexportadora que se impone en el país a principios de esa década, la yuca se convierte en un relevante transable de exportación. Pital y La Fortuna son los principales distritos productores de yuca en San Carlos. Para la economía y sociedad de ambos es fundamental la producción y exportación de yuca, sobre todo si se toma en cuenta la presencia de pequeños y medianos productores. En el caso de La Fortuna y el sector Ángeles (Peñas Blancas, San Ramón) a la producción yuquera se han incorporado con relativo éxito fincas pertenecientes a asentamientos campesinos establecidos en décadas pasada por el Instituto de Desarrollo Agraria (IDA).

Por lo anterior, un equipo interdisciplinario de la Sede San Carlos del Instituto Tecnológico de Costa Rica (ITCR) seleccionó y estudió una franja territorial entre los distritos de La Fortuna (San Carlos) y Peñas Blancas (San Ramón), en donde existen varias fincas y empacadoras dedicadas a la siembra, procesamiento y exportación de yuca. El proyecto, ejecutado entre 2006 y 2008, busca mejorar la eficiencia de la cadena productiva de la yuca al tiempo que indaga en algunos aspectos sociales y laborales relacionados con esta actividad.

Como un adelanto a otros resultados obtenidos durante el proyecto, este artículo ofrece una caracterización histórica y socioeconómica de la franja yuquera investigada.

\section{Breve caracterización socioeconómica de la franja territorial yuquera}

Por los escasos registros actualmente disponibles, la zona en estudio se empezó a colonizar a fines de la década de 1930 (Vargas, 1986). (En la figura I se presenta un mapa con las comunidades en las que se realizó el estudio). Durante el periodo 19501990 la principal actividad económica fue la ganadería, de carne en los inicios y de doble propósito a partir de 1970. La mayor parte de los suelos fueron transformados en pastizales luego de una deforestación masiva, que en el periodo citado también afectó gran parte del territorio sancarleño (Rodríguez, 2003a). En la figura 2, que contiene información correspondiente a 1992, cuando la nueva estrategia agroexportadora estaba plenamente consolidada en San Carlos, el uso del suelo estaba dominado todavía por los repastos. Estudios realizados después, y referenciados en el cuarto informe del Estado de la Nación (1997) que tenía un capítulo especial dedicado a la región Huetar Norte, señalaban que la ganadería estaba perdiendo importancia en la franja investigada y en zonas vecinas, y que en suelos antes dedicados a la ganadería se sembraban productos como los tubérculos, el plátano, la caña de azúcar y el arroz. A pesar del relativo declive del sector pecuario, los repastos seguían ocupando la mayor parte de los suelos, situación que confirman estudios más recientes (Rodríguez, 2006). 


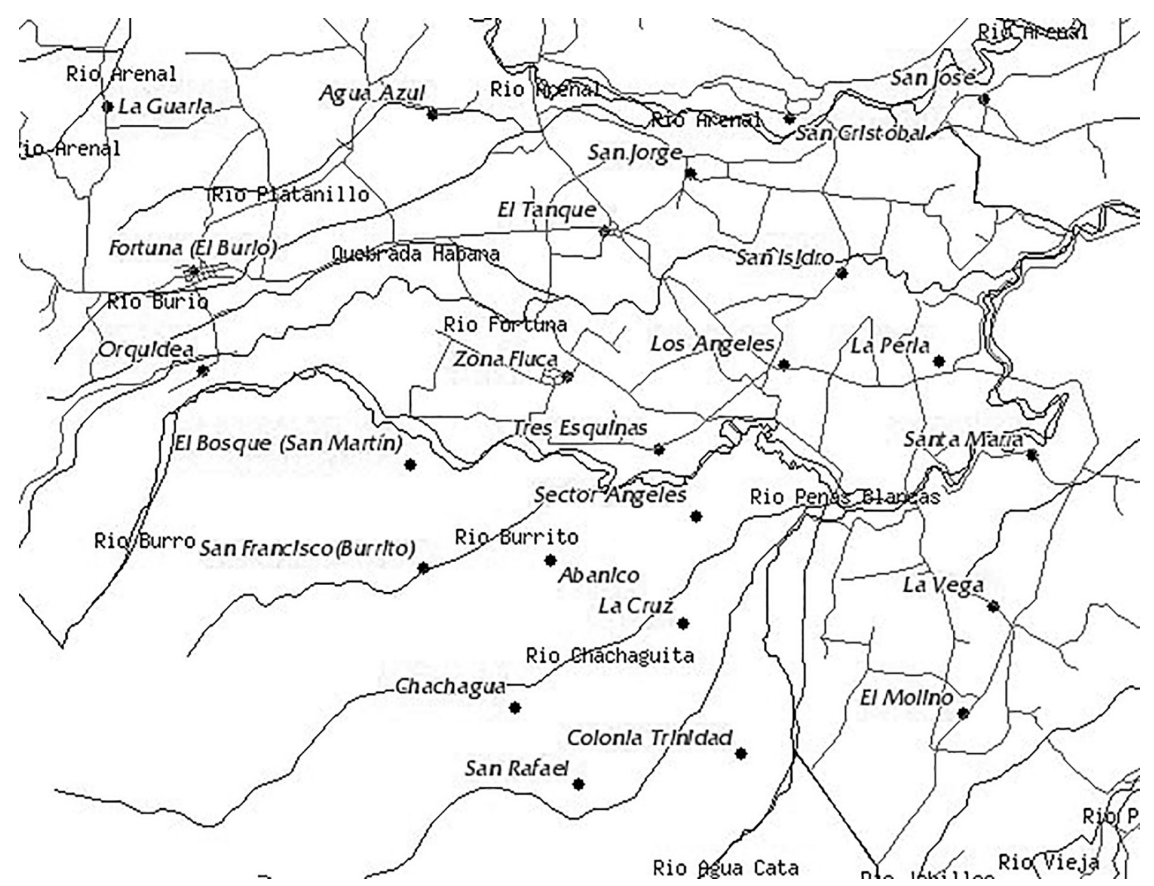

Figura I. Mapa con las comunidades de la franja territorial seleccionada para la investigación.

\section{Capacidad de uso del suelo}

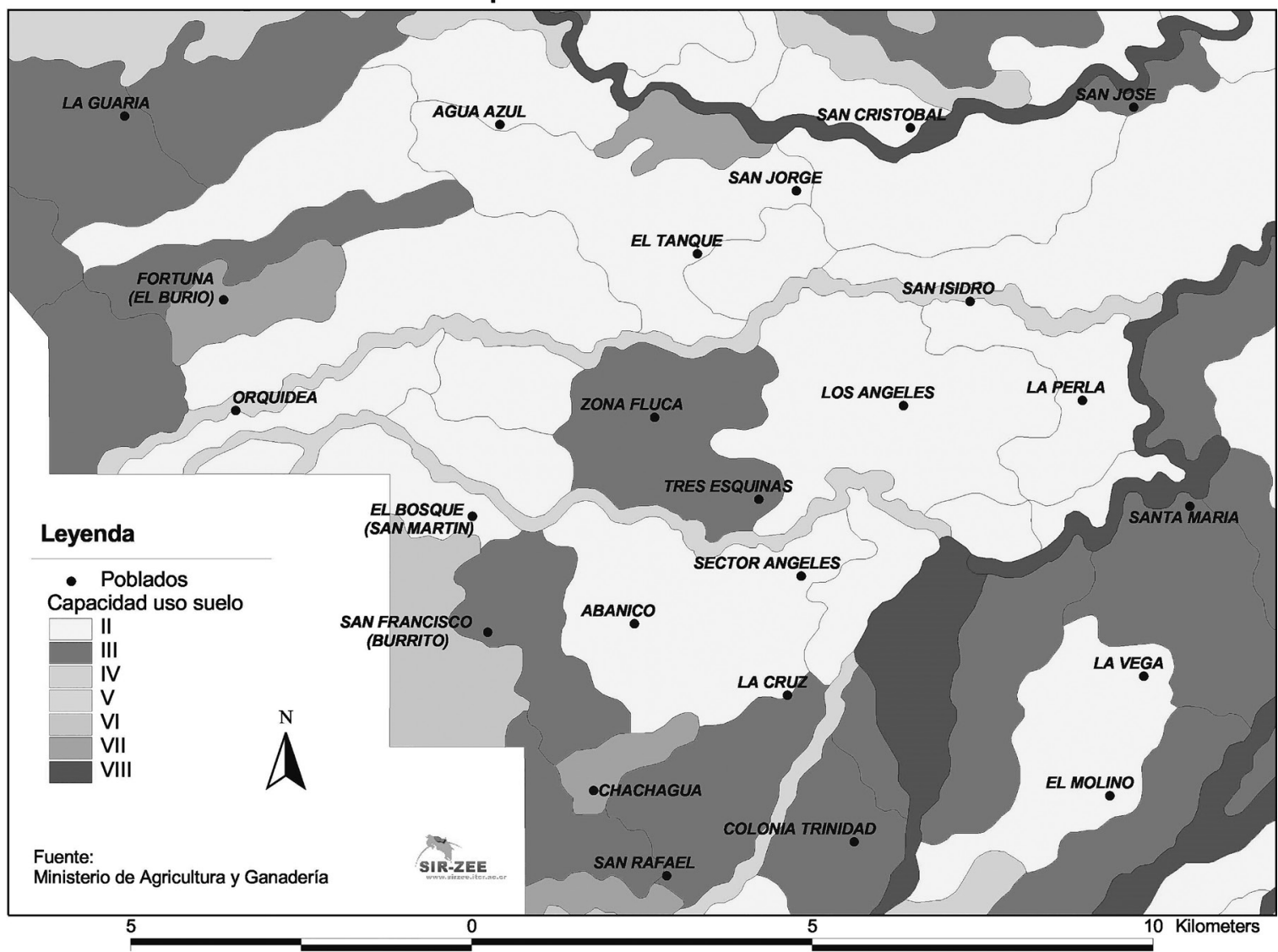

Figura 2. Uso del suelo en la franja de estudio. 
Un hecho importante fue el establecimiento en la década de 1970, con la participación del IDA, de varios asentamientos campesinos, como Zonafluca, Sector Ángeles, El Burrito o El Brujo (ver figura 3), que en los primeros años se dedicaban a la ganadería, el cultivo de plátano y los granos básicos, pero que desde 1990 incursionan en la producción de raíces y tubérculos, con el predominio de la yuca (Rodríguez, 2003a). En la actualidad, estas son las principales actividades productivas que ocupan a la población de la franja estudiada, constituyendo a la vez el sustrato económico del tejido social de las comunidades locales.

Las acciones referidas no fueron aisladas sino que formaban parte de un amplio programa del Estado costarricense durante el periodo 1960-1982 (aunque en la zona norte se extendió por algunos años más), cuyo propósito era repartir la tierra, para lo cual fraccionó los baldíos públicos o compró haciendas pertenecientes a grandes propietarios. "Hacia el final del siglo $X X$, el otorgamiento de parcelas en los asentamientos sumaba ya más de 200.000 hectáreas y beneficiaba a unas 14.000 familias en 186 colonias. Dicha política fundiaria cambió sustancialmente la estructura agraria regional" (Faure y Samper, 2004: II). Según Rodríguez y Maitre d'Hotel (2004: 46), fueron 18.000 las familias beneficiadas con el reparto de parcelas. De todos modos, lo importante es destacar que la franja territorial estudiada se benefició mucho con las políticas agrarias durante el periodo desarrollista (1950-1982), políticas que cambiarán a partir de 1982, cuando el Estado dejó de ser un actor de primer orden en la distribución de la tierra en el mundo rural, dejando el acceso al recurso tierra en manos de los mecanismos del "libre mercado" (Rodríguez y Maitre d'Hotel, 2004).

Los agricultores más perjudicados con el cambio de política luego de 1983 serán los productores de alimentos, ya que las políticas del Estado privilegian los productos no tradicionales de exportación (con financiamiento, asistencia técnica, incentivos fiscales, etc.) y, como ya fue señalado, promueven activamente la "reconversión productiva". En la franja estudiada los agricultores debieron asumir este reto (pues la producción de alimentos era una de sus actividades más relevantes); quienes no pudieron hacerlo debieron abandonar la actividad, vender sus parcelas, emplearse en las empacadoras que

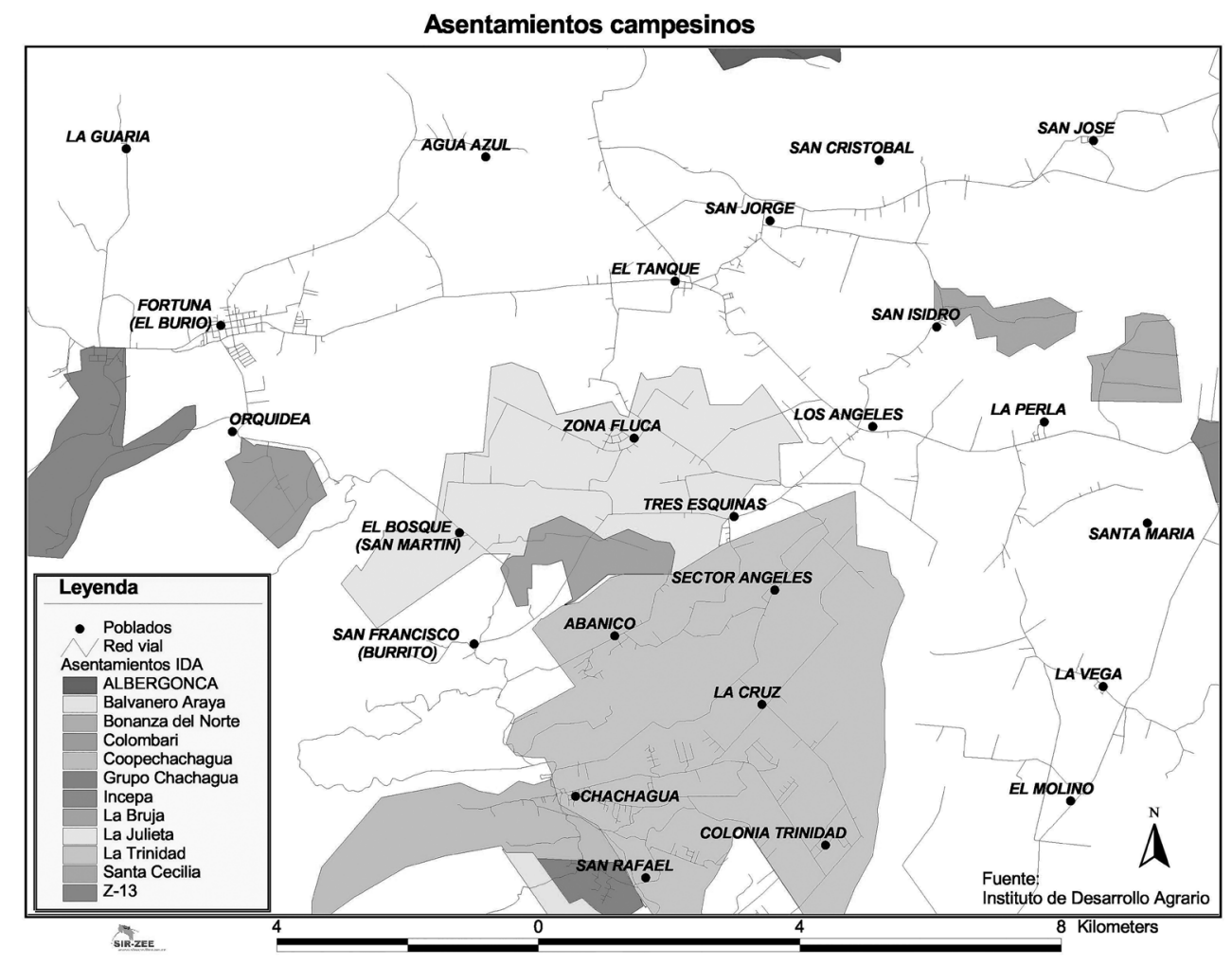

Figura 3. Asentamientos campesinos establecidos en la franja territorial yuquera estudiada. 
proliferan en la región desde mediados de la década de 1980 o emigrar a los centros urbanos del Valle Central, suerte que también corrieron miles de familias campesinas en el resto del país.

Los datos muestran -y la investigación realizada por los autores así lo corrobora- que en la franja en estudio muchos agricultores pudieron integrase bien a los grandes mercados internacionales, lo que ha repercutido en un mejoramiento del nivel de vida de parte de su población; sin embargo, la yuca es fundamentalmente un producto étnico (latinoamericanos, asiáticos y africanos) en los principales mercados consumidores (Estados Unidos y Europa). Eso significa que el crecimiento de la exportación de yuca hacia los principales mercados consumidores depende en buena medida del progreso económico y social que obtengan las poblaciones de origen latinoamericano y africano. Esta circunstancia hace vulnerables las exportaciones de yuca cuando esos grupos étnicos se ven afectados por crisis económicas en los países donde residen. Actualmente ese es el caso para muchos residentes latinoamericanos en Estados Unidos, y latinoamericanos y africanos en algunos países europeos, como España o Italia. Estados Unidos y España experimentan desde 2007 una fuerte recesión en el sector de la construcción, que ha dejado sin empleos a miles de inmigrantes oriundos de América Latina.

\section{Periodización y caracterización históricas de la franja territorial yuquera estudiada \\ Época precolombina}

Algunos estudios señalan que el poblamiento del actual territorio sancarleño, en donde se ubica la mayor parte de la franja territorial estudiada, se remonta a unos 10000 años (Guerrero, 1994). Durante este periodo de tiempo los pueblos que la habitaban evolucionaron desde la caza, la pesca y la recolección hasta grupos humanos socialmente estratificados dependientes de la agricultura, que trabajaban la cerámica, la piedra y los metales (Troyo, 1990, Guerrero, 1994). En la región objeto de estudio o en sus alrededores (como en el asentamiento campesino El Jaurí) se han encontrado valiosas piezas arqueológicas, especialmente de piedra (Guerrero, 1994). Guerrero (1994) divide la historia precolombina del norte costarricense, que incluye la franja estudiada, del siguiente modo:
I. Grupos de cazadores y recolectores (100002000 AC).

2. Primeros agricultores y aparición de la cerámica (2000-500 AC).

3. Grupos de agricultores tempranos, con la aparición de las primeras jerarquías, correspondiente a los cacicazgos (500 AC-500 DC).

La periodización de Guerrero es muy parecida a la hecha por Fonseca (1992) para la historia precolombina de Costa Rica, aunque Fonseca agrega el cacicazgo evolucionado, que fue la forma de organización social mas extendida en suelo costarricense a la llegada de los españoles a mediados del siglo XVI, y que se supone también existió en suelo sancarleño, por lo menos en algunos lugares, como Venecia, concretamente el sitio arqueológico Cutrís, el mas importantes hallado hasta ahora en la región (Hoopes, 1994).

Lamentablemente para la franja objeto de investigación no existen estudios más concretos sobre las características demográficas, económicas, sociales y culturales de los pueblos que la habitaron en la época precolombina. Es una de las tantas lagunas que presenta el conocimiento de la historia antigua del país, especialmente de regiones como San Carlos, que siguen ocupando un sitio marginal en la historiografía costarricense. Este desconocimiento no solo es del periodo precolombino, que en este apartado se esboza en sus trazos más generales, sino del conjunto de la historia sancarleña y norteña, aunque justo es reconocer que en los últimos años se vienen haciendo esfuerzos por remediar, aunque sea parcialmente, esta situación.

Es en el último periodo mencionado en la clasificación de Fonseca (1992) cuando se produce un mayor desarrollo civilizatorio: la concentración de la población se intensifica; existen aldeas con varias viviendas y con caminos de piedra, así como calzadas y diversas obras públicas, siendo relevante la presencia de los poderes político y religioso que recaen sobre el cacique, quien al mismo tiempo realiza la redistribución de los bienes y productos, rasgo este característico de los cacicazgos costarricenses (Fonseca, 1992; Ferrero, 1993, 200 I).

El proceso productivo se hace con instrumentos de piedra (líticos): tala de bosques, preparación de terrenos; con estos instrumentos se fabrican aquellos utensilios empleados en el procesamiento 
de alimentos, como los metates -que constituyen algunos de los más bellos ejemplos de la arqueología precolombina costarricense-, manos de moler, machacadores, morteros y pistilos (Ferrero, 2000).

Existió una diferenciación entre las viviendas de las élites y las del resto de la población. Las élites vivían en las aldeas más importantes construidas con muros de piedras, montículos y caminos. Quienes no pertenecían a ellas habitaban en aldeas más pequeñas, en donde los edificios estaban hechos de madera, mientras las palmas se utilizaban para confeccionar los techos (Ferrero, 200 I).

Las aldeas más importantes del norte costarricense, y en especial los personajes principales que en ellas habitaban, tenían gran relación entre sí y con pueblos de otras regiones, como por ejemplo Guanacaste, con los que comerciaban, entre otros productos, cerámica polícroma y sal (Hoopes, 1994). Con los pueblos del Atlántico o de la región central comerciaban oro (Guerrero, 1994). En San Carlos se han encontrado sitios con las características anteriormente señaladas en los actuales distritos de Venecia, Pital, Ciudad Quesada (San Vicente) y La Fortuna (donde se ubica la franja investigada) (Troyo, 1990, Guerrero, 1994).

Durante los siglos XVI al XVIII las llanuras del Norte fueron refugio, al igual que las montañas de Talamanca, para muchos indígenas que no querían verse sometidos al trabajo forzado de las encomiendas (Ibarra, 1990, Quirós, 1990). Tanto para la franja estudiada como para el conjunto del actual San Carlos se carece de datos ciertos sobre los grupos humanos que lo poblaron durante estos siglos y los sitios exactos que ocuparon. Un distinguido arqueólogo que ha estudiado la región señala:

Aunque los datos etnohistóricos son incompletos e insuficientes para explicar con exactitud lo que sucedía en la mencionada región (Huetar Norte) desde el siglo XVI hasta el XVIII, lo que hace muy difícil tener un panorama bien claro de los grupos étnicos existentes. Lo que es importante de rescatar es la diversidad cultural que había coexistido en un medio ambiente particular, como lo es el bosque tropical. Para el siglo XVI, y muy posiblemente varios años antes, las llanuras del Norte estaban pobladas por grupos como los Votos, Corobicíes, Ramas, Guatuzos y Huetares, todos con una filiación lingüística proveniente del Chibcha. Además, estaban en relación con grupos Chorotegas y

Nicaraos (Guerrero, 1994: 61).

Historia reciente: de finales del

siglo XIX hasta 1950

La franja estudiada, como en general el territorio sancarleño, fue de colonización tardía. La colonización de San Carlos empieza tímidamente a mediados del siglo XIX pero se intensifica a fines de esa misma centuria (Molina, 1978). Esta colonización es una de las consecuencias que tendrá en la sociedad, la economía y la demografía del país la agroexportación cafetalera, ya que promueve la conquista y extensión de la frontera agrícola, siendo la sección occidental del Valle Central en la provincia de Alajuela una de las más rápidamente ocupadas (|830-|880), aspecto de importancia porque con el tiempo de ahí saldrán muchos de los pobladores que en oleadas sucesivas irán arribando a San Carlos, cuyo extenso territorio formaba parte de la móvil frontera agrícola del país (Hall, 1978; González, 199|; Hilje, 1991). Sobre este hecho la historiadora Brunilda Hilje anota que:

Desde el punto de vista de la inmigración nacional, San Carlos está en el límite de la frontera agrícola del proceso colonizador que se inicia en la primera mitad del siglo XIX en el occidente de Alajuela. Fue esa misma región occidental por su cercanía a San Carlos, de donde parten nuevos movimientos migratorios. Palmares, uno de los primeros asentamientos de las migraciones cafetaleras (...) es el que proporciona en mayor medida el elemento humano migrante a San Carlos (Hilje, |991: 46).

Otros cantones que suministran abundantes colonizadores a San Carlos son Grecia, Naranjo, San Ramón y Alfaro Ruiz (Molina, 1978; Vargas, 1986).

Algunos historiadores no le atribuyen exclusivamente al café la responsabilidad en la extensión de la frontera agrícola del país, sino que añaden otras actividades productivas que también incidieron en ese proceso. Samper (|99|), por ejemplo, menciona la ganadería, indicando que a finales del siglo XIX se inicia en las secciones altas del Valle Central la producción de leche, actividad que intensifica la competencia por el uso de los suelos, cuyo principal cultivo seguirá siendo, no obstante, el café. La extensión de las actividades agropecuarias, al tiempo que ahonda el proceso de privatización de las 
tierras comunales, herencia de la colonia española, y la concentración de la propiedad, agrava la escasez de tierra, que hizo necesario abrir nuevos frentes de colonización, surgiendo San Carlos como una opción. Por eso, a medida que

los potreros de uso común eran reducidos a dominio particular y dedicados a la agricultura, se hacía necesario incorporar nuevas tierras ganaderas a mayor distancia, de manera que la frontera de colonización era, en buena medida, pecuaria. Al acercarse el fin de siglo, esta expansión de la ganadería había desbordado los límites del Valle Central, por el norte rumbo hacia San Carlos, y también en otras direcciones. (Samper, 1991: 27).

La primera zona de San Carlos en ser ocupada por los migrantes provenientes del occidente del Valle Central estuvo comprendida entre los actuales Santa Clara (distrito de Florencia) y Terrón Colorado (Vargas, 1986). Si embargo, esta colonización tuvo poco éxito en razón de las pésimas vías de comunicación, el inhóspito clima, las enfermedades, etc. (Molina, 1978). Con los asentamientos en el piedemonte (estribaciones del norte de la Cordillera Volcánica Central) a fines del siglo XIX y principios del siglo XX, con La Unión (luego Ciudad Quesada) como centro más importante, se facilita la ocupación de San Carlos, pues paulatinamente se van poblando los territorios de los actuales distritos de Aguas Zarcas, Venecia, Pital y La Fortuna, este último, en donde se ubica la mayor parte de la franja territorial objeto de estudio, a partir de mediados de la década de 1930 (Molina, 1978; Rodríguez, 2006).

Sobre el carácter de esa primitiva colonización, la citada historiadora Brunilda Hilje señala:

Se conserva el carácter de grupos familiares, las haciendas constituyen el origen de los diferentes poblados. Luego, el pueblo tipo hacienda, con edificios administrativos, casa del dueño y ranchos para peones, desaparece para dar paso a viviendas dispersas, con unidades familiares de producción. Los pobladores pueden catalogarse como propietarios dedicados a cultivos de subsistencia con vínculos comerciales débiles entre sí y los poblados mayores del Valle Central, a causa de las deficiencias de las vías de comunicación. El comercio se orienta hacia Nicaragua, por el Río San Juan y una vía terrestre que se utiliza para traer ganado de ese país (Hilje, |991: 48).

Se trata, por tanto, de una agricultura de subsistencia; los pocos excedentes se colocan localmente. En cambio, la actividad ganadera, de acusada relevancia desde los mismos inicios de la economía regional, abastece al mercado de Alajuela y a los pobladores del Valle Central, transformándose en un vínculo económico, aunque débil, entre la región y el resto del país (Molina, 1978).

La economía del cantón -al menos la constituida por los territorios que paulatinamente se van poblando y son puestos a producir- mantendrá ese carácter hasta mediados del siglo $X X$, cuando puede afirmarse que se integra plenamente al resto de la economía costarricense (con la leche, la madera, los granos básicos, el azúcar, los tubérculos, etc.) y al mercado internacional con productos como la carne y el azúcar. La expansión económica y de la frontera agrícola atrae gran cantidad de inmigrantes, que provienen de los cantones vecinos y de lugares como Puntarenas, Guanacaste y Puriscal (Molina, 1978).

Integración al mercado nacional e internacional (1950-1985)

Desde la década de 1950 hasta mediados de la de 1970, San Carlos será un importante destino para las corrientes migratorias costarricenses, registrando tasas muy favorables en la relación migración/inmigración (Molina, 1978). La razón de ello es sencilla: el norte sancarleño y los cantones fronterizos con Nicaragua, junto a las llanuras del Atlántico y a las de la Fila Costeña en la zona sur del país, se convierten en la última frontera agrícola para quienes buscar reproducir su condición de productores independientes, y que ya no encuentran sitio ni en Guanacaste ni en el Valle Central (Rodríguez, 2002). Incluso en las más antiguas regiones colonizadas de San Carlos se clausuran las posibilidades de acceder a la propiedad de la tierra, lo que motiva a muchas familias sancarleñas a unirse a los inmigrantes de otras partes del país con el objetivo de poblar las extensas llanuras del norte (Rodríguez, 2002). Varios de estos migrantes se dirigen hacia la zona seleccionada en esta investigación, cuyos bosques son desmontados para dejar paso a las sementeras, los potreros y los pastizales (Rodríguez, 2003a,b). 
A medida que avanzan y se agotan los frentes de colonización, la tierra -cuya propiedad experimenta un progresivo acaparamiento, motivo posterior de varios conflictos agrarios- se dedica en su mayor parte a la ganadería extensiva de carne, aunque también a productos comerciales como la caña de azúcar (Molina, 1978). La tierra restante está constituida por suelos de poca calidad, con vocación forestal, poco aptos para fines agrícolas y aún menos para la ganadería (MAG, 2000), situados en lugares de difícil acceso, con pésimas vías de comunicación para sacar al mercado la producción, al principio de subsistencia pero que a medida que se profundizan las relaciones capitalistas en el agro sancarleño se dirige más al mercado (Rodríguez, 2002).

Este gran movimiento colonizador llega hasta principios de la década de 1980, cuando la frontera agrícola de San Carlos se acaba. En adelante los campesinos que por alguna razón pierdan sus tierras ya no tienen a su alcance frentes agrícolas hacia los cuales dirigirse para reconstituir su condición de productores independientes, enfrentándose a la alternativa de proletarizarse o emigrar, hechos ambos que se aceleran a partir de mediados de esa década, cuando se inicio un nuevo ciclo histórico para el agro costarricense (Estado de la Nación, 1996, Rodríguez y Maitre d'Hotel, 2004, Faure y Samper, 2004).

En estos sitios apartados de la frontera agrícola, la presencia del Estado durante casi todo este periodo será marginal y, con frecuencia, inexistente, por lo cual la población tendrá muchas dificultades para acceder a los servicios básicos (electricidad, acueductos), sociales (educación, salud, vivienda, recolección de basura, etc.) y los relacionados con la producción (crédito y asistencia técnica). (Rodríguez, 2002). Como la producción de estos lugares tenía serios obstáculos para integrarse al resto de la economía del país y no se dirigía al mercado externo, sector privilegiado por las políticas públicas de inversión social y de infraestructura, el Estado costarricense no se preocupa por tener una activa presencia en ellos. Junto a la explotación económica de los intermediarios, que compran la producción a precios irrisorios, estos campesinos y sus familias se ven abandonados por un Estado que concentra sus actividades y programas en las zonas urbanas o en las áreas rurales ligadas más estrechamente a los mercados nacionales e internacionales. Estos productores perderán sus tierras y emigrarán al centro del país cuando las políticas aperturistas y de marcado sesgo anticampesino se implementen a partir de 1985 (Faure y Samper, 2004).

Como se verá luego, sobrevivirán los productores capaces de adaptarse a los nuevos tiempos y sus exigencias. Los productores de la franja objeto de estudio constituyen uno de los ejemplos exitosos de reconversión productiva y de integración a los mercados internacionales con nuevos productos de exportación, como las raíces y tubérculos, aunque no en condiciones plenamente satisfactorias (Weller, 1997).

Durante este periodo, a cambio de los productos agropecuarios y de las materias primas, San Carlos recibirá bienes industriales de las empresas asentadas en los principales centros urbanos del Valle Central. La economía de San Carlos se especializa en la producción de materias primas agropecuarias y forestales destinadas a las empresas asentadas en el Valle Central o fuera del país. El valor agregado de la producción regional se genera externamente. Esto significa que los empleos y la riqueza también se generan externamente a la región (Rodríguez, 200 I).

Analizando las consecuencias de estas asimetrías entre regiones desde el periodo desarrollista (19501982) en adelante, brecha que tiende a ensancharse por los principios que conducen la actual administración neoliberal del Estado, escribe José Luis Vega:

Hemos asistido al hecho de que se produjo, en casi todas las regiones periféricas, una importante transferencia de ingresos fuera del sector agrícola, con la consiguiente contracción y aumento local de la pobreza, o al menos la imposibilidad de superarla; eso, a su vez, ha rendido evidentes beneficios a los sectores urbano-industriales y burocráticos (bajos precios de los artículos y alimentos, y materias primas baratas) radicados en la poderosa región central del país. Por otra parte (...) la mencionada penalización y hasta saqueo del sector agrícola ha repercutido y seguirá repercutiendo sobre un acrecentamiento del desequilibrio regional mayor; es decir, aquel que se da entre la región central y el resto de las periféricas que se han transformado en una especie de 'bloque' territorial unitario, subprivilegiado y marginal en muchos aspectos (Vega, 1997: 25).

Esta es una de las principales razones que explican el limitado dinamismo que históricamente han pre- 
sentado las actividades productivas de la región, que se continúa en los nuevos productos de exportación que se van a imponer luego de 1985, y que se expresa en las dificultades para mantener en el largo plazo tasas sostenidas de crecimiento, para darle valor agregado a la producción y para establecer vinculaciones fuertes con los distintos sectores de la economía regional. Adicionalmente, el bajo nivel tecnológico y la casi nula innovación del modelo de exportación no tradicional han sido señalados por autores como Sepúlveda et al. (2002), (Fernández, 2004) y Vargas $(2002,2007)$ como causantes del escaso dinamismo de estas actividades, así como de su limitada capacidad para influir positivamente en otras actividades económicas fuera del sector estrictamente agropecuario, lo cual también incide en que los espacios rurales que albergan ese tipo de producción y de empresas no estén en capacidad de iniciar procesos sostenidos de desarrollo socioeconómico, al tratarse de actividades y empresas agropecuarias (y agroindustriales) poco competitivas, incapaces de gestar procesos de innovación tecnológica acumulativos dentro del propio sector, y expansivos hacia otros sectores económicos y otros ámbitos territoriales. Esta situación es generalizable al conjunto de la agroexportación costarricense (Fernández, 2004; Rovira, 2004; Vargas, 2007).

La franja territorial investigada es un ejemplo de lo que acaba de afirmarse, y que se plasma en estudios previos realizados en algunas comunidades de la franja (Rodríguez, 2003a,b) y en los propios resultados del presente trabajo.

Así como actividades de gran innovación tecnológica y alta competitividad transmiten su dinamismo o otras actividades y regiones, la ausencia de tales características tiene el efecto contrario, condenando las zonas rurales a crisis cíclicas, al estancamiento económico y a bajos niveles de desarrollo humano, social y ambiental (Pérez, 200 I; Carmen, 2004; Vargas, 2007).

Esta situación no es casual ni paradójica, sino la consecuencia de un modelo de crecimiento diseñado para facilitarle las condiciones de inversión, ganancia y acumulación a los grandes actores de la globalización (las empresas transnacionales, precisamente), y no para crear dinámicas autónomas, ya sean regionales o nacionales, de desarrollo autocentrado. Aunque este modelo pueda generar desarrollo socioeconómico en territorios que hayan aprove- chado las oportunidades ofrecidas, el éxito siempre es limitado y no sostenible en el tiempo. Un autor recapitula muchas de las reflexiones de los párrafos anteriores con estas palabras:

La globalización significa la creación de un mercado mundial cada vez más integrado, que responde a las necesidades de las unidades económicas dominantes en el mundo actual, las empresas transnacionales. Esto supone una reestructuración relativa de las relaciones económicas, en la que todos los espacios, por así decirlo, deben ser libres para ese capital globalizado. En este sentido, los espacios para esquemas de desarrollo estructural, basados en un crecimiento armónico de los diversos sectores económicos y asentados en un desarrollo importante de los mercados internos y regionales, son prácticamente inexistentes, ya que no son funcionales, sino, más bien, contradictorios con los intereses de las grandes transnacionales (...). Esto no significa sino volver a los parámetros tradicionales del subdesarrollo, bajo los cuales nuestros países han especializado sus economías en función del mercado mundial, consagrando en nuestro caso con su vocación agroexportadora de productos tropicales, en condiciones totalmente desfavorables en el mercado mundial respecto a las condiciones de venta y precios. La división internacional del trabajo, bajo la égida de la globalización, significa la consagración en el altar del neoliberalismo y la dominación mundial del capitalismo, de nuestra condición de países subdesarrollados y dependientes, con economías que solo son funcionales en el marco del intercambio desigual. Esta forma de vinculación con la economía global no significa otra cosa que el mantenimiento de la pobreza y el subdesarrollo, y condiciones de vida deficitarias para la mayoría de la población" (Fernández, 2004: 229-231, cursivas nuestras).

Las desventajas de esta asimetría para San Carlos y otras zonas periféricas costarricenses ya fueron estudiadas con detalle en el trabajo pionero de Altemburg et al. (1990), quienes aconsejaban darle mayor valor agregado a la producción regional mediante la agroindustria como motor principal de un proceso que incluiría otras ramas productivas (como la metalmecánica, por ejemplo). Este proceso debería conducir, según Altemburg et al. (1990), a la formación de empresas regionales cada vez más 
vinculadas entre sí (al interior de lo que denominaron complejos agroindustriales, encadenamientos hacia adelante y hacia atrás dentro de un producto agropecuario determinado, y entre estos complejos agroindustriales y otros sectores de la economía regional, como el industrial, el financiero, el comercial o el de transportes) que favorecerían la creación de empleos con mano de obra calificada y adecuadas remuneraciones. Esta propuesta se encaminaba a paliar una situación de "colonialismo interno", ya que reproducía en el plano nacional la situación de dependencia y explotación que la economía costarricense experimenta respecto a los países más desarrollados (Rodríguez, 200I, 2002).

Es imposible abordar estudios sobre la producción y agroexportación en territorios rurales sin considerar el atraso relativo que el agro ha tenido históricamente (y que se expresa, entre otros aspectos, en sus mayores índices de pobreza, analfabetismo, hacinamiento, menor cobertura del seguro social, menor acceso a los servicios básicos, emigración, etc.) y, aspecto ya mencionado, el papel marginal que las políticas del Estado le han asignado, especialmente en la inversión pública (Estado de la Nación, 1997, Pérez, 1997, Román, 1997).

Por eso, cualquier estudio sobre el agro debe considerar esta desventaja histórica de las comunidades rurales, que con el tiempo provoca que los déficits económicos, sociales e institucionales acumulados sean más difíciles de resolver, situación que se complica cuando, como ha venido sucediendo en Costa Rica en los últimos 25 años, la inversión pública está sometida a diferentes restricciones (Rovira, 2004, Vargas, 2007, Sojo, 2008).

Trabajos posteriores como los de Sepúlveda (2002), Chavarría y Sepúlveda (2002) y Rojas et al. (2002) coinciden con dicho diagnóstico, enfatizando la importancia de los distintos vínculos que las empresas ubicadas dentro de un cierto ámbito territorial deberían establecer para conformar lo que denominan "cadenas productivas". En estos trabajos se vuelve a poner de relieve la importancia de la organización de los productores y el factor institucional como catalizadores de procesos regionales de desarrollo ambientalmente sostenibles, socialmente equitativos y sostenidos en el tiempo.
Para Sepúlveda et al. (2003), Mora (2007) y Sojo (2008), el papel de las instituciones públicas es clave y sus acciones deberían encaminarse en una doble vía: el mejoramiento de las condiciones de vida de la población (educación, salud, vivienda, servicios básicos) y el mejoramiento de la competitividad de las empresas (investigación y transferencia tecnológica, capacitación, construcción de infraestructura, etc.). Pero de acuerdo con Sharp (1997) y Sobrado y Rojas (2006), el grado y la magnitud de la intervención pública depende en buena medida del nivel organizativo interno (empresarial y/o comunal) y de su capacidad de incidencia en la toma de decisiones del Estado.

Sin embargo, como se indicara, las últimas décadas han visto la implementación de políticas tendientes a reducir los alcances de la intervención estatal, políticas que han tenido serios impactos especialmente en el mundo rural, según lo discuten trabajos como los de Román (1997), Spoor (200 I), Tejo (200 I) y Vargas $(2002,2007)$. Por su relevancia, tales aspectos serán retomados posteriormente como insumo teórico para analizar la situación observada en la franja territorial bajo estudio.

Recapitulando lo comentado en los párrafos precedentes, otorgar valor agregado a la producción es un reto tan imperativo como ineludible para las empresas, la economía y la sociedades locales o microrregionales, diagnóstico en el que coinciden, aparte de los autores mencionados, los estudios y análisis del Estado de la Nación (1997) -cuyo capítulo especial estaba dedicado a San Carlos y la región Huetar Norte-, Fernández (2004) o Láscaris (2004).

La nueva agroexportación y sus consecuencias socioeconómicas (I 985 al presente)

La relación de la economía regional (San Carlos y comunidades que sin pertenecer a su ámbito territorial, sí mantienen con él estrechas vinculaciones económicas y sociales, caso de los distritos ramonenses de Peñas Blancas, Chachagua y Bajo Rodríguez, o de Río Cuarto, distrito de Grecia) con el mercado internacional se verá fortalecida a partir de la década de 1980 con una gran variedad de nuevos productos (piña, naranja, raíces y tubérculos como la yuca, especies, ornamentales, entre otros) y servicios (el turismo, fundamentalmente) (Rodríguez, 2006). 
Esto iba a significar para muchas empresas agropecuarias intensos, y a veces acelerados, procesos de reconversión productiva, exitosos en algunos casos, fallidos en otros. Autores como Mora (1990), Fernández (1994, 1996), Monge (1994), Morera, (1996), Pérez (1997), Rivera y Román (1997) o Rodríguez y Maitre d'Hotel (2004) en su momento estudiaron la forma en que evolucionaban las exportaciones de los productos no tradicionales, priorizando los obstáculos enfrentados por los agricultores que se estaban pasando a los nuevos productos de exportación, especialmente quienes se habían dedicado a otras actividades. Entre las principales causas señaladas por esos autores, y que obstaculizaron o de plano impidieron la "reconversión" de muchos pequeños y medianos productores, estaban las siguientes:

- La falta de experiencia en los nuevos productos, pues efectivamente pasar de producir maíz a las plantas ornamentales, las frutas o las especies no es sencillo para quien se ha dedicado toda su vida a un determinado cultivo.

- La ausencia de suficiente capital para afrontar los costos de inversión requeridos por los nuevos cultivos.

- Las exigencias técnicas de las empresas comercializadoras, que usualmente implicaban gastos o experticias de las cuales carecían los productores en proceso de reconversión.

- Muchos de los nuevos cultivos necesitaban varios años para brindar resultados económicos satisfactorios, tiempo del que no disponían los productores pequeños y medianos, cuyas capacidades de acumulación y reinversión en tales actividades eran pocas.

- El alto costo del paquete tecnológico requerido por los nuevos cultivos.

- Carencia de una adecuada asistencia técnica.

Un estudio realizado en comunidades situadas dentro de la franja territorial incluida en la presente investigación (o en comunidades vecinas a ella) verifica parcialmente las razones aducidas por los autores arriba citados (Rodríguez, 2003a,b). Sin embargo, algunos de estos autores, como Reuben (1990), Rivera y Román (1990) y otros como Román y
Rojas (1993), Stamm (1996) o Weller (1996) indican que, junto a microrregiones ubicadas en el Valle Central, una de las regiones costarricenses que mayor éxito han tenido con los nuevos productos de exportación ha sido precisamente el cantón de San Carlos, al menos la sección sur de la cuenca del río San Carlos, a la que Rodríguez (200l) denomina el "San Carlos histórico", por ser la que primero logró modernizar su sector agropecuario y la que mejor ha podido integrarse a los mercados nacional e internacional, razones que explican su privilegiada posición dentro de la inversión pública destinada al norte costarricense. La franja territorial seleccionada para esta investigación es ejemplo del relativo éxito obtenido con la agroexportación no tradicional. Sin embargo, quienes no pudieron "reconvertirse" en el agro costarricense durante las pasadas décadas, incluyendo regiones relativamente "exitosas" como San Carlos, debieron vender o entregar sus tierras, emplearse como fuerza de trabajo en las fincas, haciendas y empacadoras o emigrar a otras regiones, sobre todo al centro del país.

La afirmación anterior, empero, debe matizarse, pues, aunque desde fines de la década de 1980 existen estudios que analizaron este fenómeno de "descampesinización" y el consecuente colapso de la producción de granos básicos, desarrollado marcos teóricos para intentar explicarlo como parte de las nuevas dinámicas de acumulación de capital y transnacionalización del agro y sus repercusiones en los ámbitos locales (Faure y Samper, 2004 es un buen ejemplo), no hay trabajos que sobre una base empírica hayan podido cuantificar el fenómeno descrito, esto es, el número de personas y familias que abandonaron sus tradicionales actividades productivas y emigraron hacia otras regiones e incluso fuera del país (Estados Unidos, en primer lugar). En otras palabras, se trata de un fenómeno constatado pero aún no suficientemente cuantificado ni analizado.

\section{Agradecimientos}

Los autores agradecen a la Vicerrectoría de Investigación del Instituto Tecnológico de Costa Rica, por financiar el proyecto "Mejoramiento de la eficiencia en el proceso productivo de la yuca", del cual se derivó este artículo. 


\section{Bibliografía}

Altemburg, T., Hein, W. \& Weller, J. (1990). El desafí económico de Costa Rica. Desarrollo agroindustrial autocentrado como alternativa. San José: Editorial DEl.

Barquero, M. (20I0). Exportaciones y precio de yuca se desploman. Consultado: 14 de mayo 2010. Obtenido desde: http://www.nacion.com/2010-03-I2/Economia/ NotasSecundarias/Economia2298587.aspx.

Carmen, R. (2004). Desarrollo autónomo. Heredia, CR: Editorial de la Universidad Nacional. 343 pp.

Chavarría, H. \& Sepúlveda, S. (2002). Factores económicos y no económicos de la competitividad. (pp.|07-184). En: Chavarría, H., Sepúlveda, S. \& Rojas, P. (Comps.). Competitividad. Cadenas agroalimentarias y territorios rurales. San José: IICA.

Faure, G. \& Samper, M. (2004). Veinte años de apertura económica: el porvenir comprometido de la agricultura familiar en el norte de Costa Rica. Anuario de Estudios Centroamericanos 30 ( I-2): 7-26.

Fernández, M. (2006). El Tratado de Libre Comercio: Repercusiones de la apertura del mercado en el sector agropecuario de Costa Rica. (pp. 77-II3). En: Trejos, M.E. \& Fernández, M. (Eds.). Tratado de Libre Comercio Estados Unidos-Centroamérica-República Dominicana. Estrategia de tierra arrasada. San José: EUNED.

Fernández, M. (2004). La agricultura costarricense ante la globalización. Las nuevas reglas del comercio internacional y su impacto en el agro. San José: Editorial de la Universidad de Costa Rica. 322 pp.

Fernández, M. (1994). La integración de la agricultura en la región centroamericana en el marco de los procesos de apertura. (pp. 89- I52). En: Masís, G. \& Sancho, F. (Comps.). La Agricultura de Exportación en Centroamérica: opciones de desarrollo en la década de los 90. San José: UNA.

Fernández, M. (1996). La reconformación de la integración económica en América Central y la agricultura costarricense: perspectivas y estrategias para los diferentes subsectores. (pp. 245-272). En: Nuhn, H. \& Stamm, A. Apertura comercial en Centroamérica: Nuevos retos para la agricultura. San José: Editorial DEl.

Ferrero, L. (2000). Costa Rica Precolombina (6 ${ }^{\mathrm{a}}$. reimp. de I ${ }^{\mathrm{a}}$. ed.). San José: Editorial Costa Rica. 488 pp.

Ferrero, L. (1993). Los cacicazgos teocráticos. San José: Ministerio de Cultura-Comisión Costarricense $\vee$ Centenario del Descubrimiento de América. 98 pp.

Ferrero, L. (200 I). Entre el pasado y el futuro. San José: Editorial Costa Rica. 248 pp.

Fonseca, J. \& Saborío, D. (200I). Tecnología postcosecha de yuca fresca parafinada (Manihot esculenta Crantz) para exportar en Costa Rica. San José: Ministerio de Agricultura y Ganadería. 56 pp.
Fonseca, O. (1992). Historia Antigua de Costa Rica: surgimiento y caracterización de la primera civilización costarricense. San José: Editorial Universidad de Costa Rica. 260 pp.

González, E. (199|). Evolución histórica de la población de Costa Rica (1840-1940). San José: EUNED (Fascículo 9 serie Nuestra Historia). 84 pp.

González, O. (2006). Relaciones entre empresas, mercadeo y globalización. San José: Editorial Universidad de Costa Rica (Serie Cuadernos de Historia de la Cultura No. 18), 58 pp.

Guerrero, J. (1994). Arqueología de la Región Huetar Norte. En: Rodríguez, F. \& y Corrales, A. (Comp. y Ed.). Memoria Segundo Congreso Nacional de Folclore y Cultura Popular. Cartago:Taller de Publicaciones del ITCR.

Hall, C. (1978). El café y el desarrollo histórico-geográfico de Costa Rica. San José: Editorial Costa Rica-Universidad Nacional. $210 \mathrm{pp}$

Hilje, B. (1991). La colonización agrícola de Costa Rcia (18401940). San José: EUNED (Fascículo 10 serie Nuestra Historia), 90 pp.

Hoopes, J. (1994). Arqueología del Guanacaste oriental. Revista Vínculos 18/19(1-2): 69-90.

Ibarra, E. 1990. Las sociedades cacicales de Costa Rica (siglo XVI). San José, Editorial de la Universidad de Costa Rica (Colección Historia de Costa Rica), 248 pp.

Láscaris, T. (2004). Innovación tecnológica y competitividad productiva en Costa Rica. Cartago: Editorial Tecnológica de Costa Rica. 156 pp.

Ministerio de Agricultura y Ganadería (MAG). (2000). Estudios de suelos y capacidad de uso de las tierras para la zonificación agropecuaria de las regiones Huetar Norte, Atlántica y Brunca. Informe Final Región Huetar Norte. San José: MAG. 255 pp.

Molina, R. (1978). El proceso histórico-geográfico de la colonización agrícola en San Carlos ( $1850-1977)$. Tesis. Escuela de Historia, Universidad de Costa Rica, 307 pp.

Monge, H. (1994). Funcionamiento e implicaciones de la producción agrícola no tradicional: El caso de Costa Rica. (pp. 37| -457). En: Masís, G. \& Sancho, F. (Comps.). La agricultura de exportación en Centroamérica: opciones de desarrollo en la década de los 90. San José: UNA.

Mora, J. (2007). La vía cooperativa de desarrollo del agro. El caso de Copronaranjo R.L. Heredia, CR: Editorial Universidad Nacional. 262 pp.

Mora, J. (1990). Los campesinos y la exportación de productos agropecuarios. (pp. I8I-209). En: Reuben, W. (Comp.). Los campesinos frente a la nueva década. Ajuste estructural y pequeña producción agropecuaria en Costa Rica. San José: Editorial Porvenir-CECADE,

Morera, L. (1997). Organizar a los productores: ila llave para el acceso de la pequeña y mediana empresa al mercado mundial? (pp. 173-194). En: Nuhn, H. \& Stamm, A. Apertura comercial en Centroamérica: Nuevos retos para la agricultura. San José: Editorial DEl. 
Pérez, J. (200l). Globalización, Territorialidad y Comunidad: Reflexiones sobre las dinámicas locales. (pp. 189-280). En: Pérez, J.P. et al. Globalización y Comunidades en Centroamérica. San José: FLACSO.

Pérez, L. (1997). Apertura económica: Ventajas o desventajas para la pequeña producción agropecuaria? Perspectivas Rurales I: $25-42$.

Proyecto Estado de la Nación. (1996). Estado de la Nación en Desarrollo Humano Sostenible. Informe 1996. San José: Proyecto Estado de la Nación.

Proyecto Estado de la Nación. (1997). Estado de la Nación en Desarrollo Humano Sostenible. Informe 1997. San José: Proyecto Estado de la Nación.

Quirós, C. (1990). La era de la encomienda. San José: Editorial Universidad de Costa Rica (Colección Historia de Costa Rica). 380 pp.

Reuben,W. (1990). El potencial de la economía campesina en la reactivación económica y el desarrollo de Costa Rica. (pp. 2|3-24I). En: Reuben, W. (Comp.): Los campesinos frente a la nueva década. Ajuste estructural y pequeña producción agropecuaria en Costa Rica. San José: Editorial Porvenir-CECAD.

Rivera, R. \& Román, I. (1990). Ajuste estructural y alternativas productivas para los pequeños productores. (pp. |4|-|80). En: Reuben, W. (Comp.). Los campesinos frente a la nueva década. Ajuste estructural y pequeña producción agropecuaria en Costa Rica. San José: Editorial Porvenir-CECADE,

Rodríguez, F. (200 I). Región, Identidad y Cultura. Algunas reflexiones a partir del caso de San Carlos. San José: Ediciones Perro Azul.

Rodríguez, F. (2002). La cuenca del río San Carlos. Caracterización histórica, económica, social y ambiental. (pp. 18-67). En: Rodríguez, Francisco y Chaves, Adolfo (Comp.). Estudios sobre la cuenca del río San Carlos. Cartago: Taller de Publicaciones del ITCR.

Rodríguez, F. (2003a). Caracterización de los sistemas productivos y de las prácticas culturales en la subcuenca del río Peñas Blancas, cuenca del río San Carlos. Pensamiento Actual 4(5): 24-34.

Rodríguez, F. (2003b). Formas de laboreo, prácticas culturales y organización de la producción en la subcuenca del río Javillos. Tecnología en Marcha I6(I): 80-91.

Rodríguez, N. \& y Maitre d'Hotel, E. (2004). Las organizaciones frente a la evolución de las políticas públicas en Costa Rica: una relectura histórica de las estrategias de las organizaciones de productores agrícolas de la región Huetar Norte. Anuario de Estudios Centroamericanos 30(I-2): 27-50.

Rodríguez, F. (2006). Formas de laboreo, prácticas culturales y organización de la producción en la subcuenca del río Peñas Blancas, cuenca del río San Carlos. (pp. 106-144). En: Rodríguez, F. \& Chaves, A. (Comp.). Valoración del recurso hídrico de la cuenca del río San Carlos. Cartago: Taller de Publicaciones del ITCR.

Rojas, P., Chavarría, H., Romero, S. \& Sepúlveda, S. (2002). Complejos productivos: de la teoría a la práctica. (pp. $185-$
219). En: Chavarría, H., Sepúlveda, S. \& Rojas, P. (Comps.). Competitividad. Cadenas agroalimentarias y territorios rurales. San José: IICA.

Román, I. \& Rojas, M. (1993). Agricultura de exportación y pequeños propietarios en Costa Rica. San José: FLACSO (Cuadernos de Ciencias Sociales No. 61).

Román, I. (1997). Tendencias de cambio social en el proceso de modernización agrícola costarricense (1990-1996). Perspectivas Rurales 1: 72-84.

Rovira, J. (2004). El nuevo estilo nacional de desarrollo de Costa Rica 1984-2003 y el TLC. (pp. 309-346). En: FlorezEstrada, M. y Hernández, G. (Eds.). TLC con Estados Unidos. Contribuciones para el debate. San José: Universidad de Costa Rica.

Samper, M. (|99|). El trabajo en la sociedad rural costarricense (1840-1940). San José: EUNED (Colección Nuestra Historia No. I I). 82 pp.

Sepúlveda, S. (2002). Desarrollo sostenible microrregional. Métodos para la Planificación Local. San José: IICA. 314 pp.

Sepúlveda, S., Rojas, P. \& Chavarría, H. (2002). Competitividad y cadenas agroalimentarias. (pp. 29-62). En: Chavarría, H; Sepúlveda, S; Rojas, P. (Comps.). Competitividad. Cadenas agroalimentarias y territorios rurales. San José: IICA.

Sepúlveda, S., Rodríguez, A., Echeverri, R. \& Portilla, M. (2003). El enfoque territorial del desarrollo rural. San José: IICA. I57 pp.

Sharp, R. (1997). Organizarse para el cambio: el poder del pueblo y el papel de las instituciones. (pp. 63-100). En: Sepúlveda, S. \& Edwards, R. (Comps.). Desarrollo Sostenible. Organización Social, Marco Institucional y Desarrollo Rural. San José: IICA.

Sobrado, M. \& Rojas, J. (2006). América Latina: crisis del Estado clientelista y la construcción de repúblicas ciudadanas. Heredia, CR: Editorial de la Universidad Nacional. 227 pp.

Sojo, C. (2008). La modernización sin Estado. Reflexiones en torno al desarrollo, la pobreza y la exclusión social en América Latina. San José: FLACSO. 256 pp.

Spoor, Max. (200I). Incidencia de dos décadas de ajustes en el desarrollo agrícola de América Latina y el Caribe. (pp. 135- 164). En: David, B. (Comp.). Desarrollo Rural en América Latina y el Caribe. Santa Fé de Bogotá: CEPAL-ALFAOMEGA.

Stamm, A. (1996). ¿Una nueva dinámica para las zonas rurales? Relaciones intersectoriales y efectos territoriales del cambio en el modelo de desarrollo de Costa Rica. (pp. 23-48). En: Nuhn, H. \& Stamm, A. Apertura comercial en Centroamérica: Nuevos retos para la agricultura. San José: Editorial DEl.

Tejo, P. (200 I). El modelo agrícola de América Latina en las últimas décadas. (pp. 89-134). En: David, B. (Comp.). Desarrollo Rural en América Latina y el Caribe. Santa Fé de Bogotá: CEPAL-ALFAOMEGA.

Troyo, E. (1990). San Carlos dentro del marco arqueológico costarricense. Revista AKBAL I: 6-7.

Vargas, A. (1986). Sinopsis histórica del cantón de San Carlos. Ciudad Quesada: Municipalidad de San Carlos-Grupo Cultural Trapiche. 84 pp. 
Vargas, L.P. (2002). Costa Rica. 1985-1 997. Liberalización y ajuste estructural o la autodestrucción del neoliberalismo. San José: EUNED, 374 pp.

Vargas, L.P. (2007). La estrategia de liberalización económica (Periodo 1980-2000). San José: Editorial de la Universidad de Costa Rica Serie Cuadernos de Historia de las Instituciones de Costa Rica, No. 9). 68 p.

Vega, J.L. (1997). Panorama de la pobreza rural en Costa Rica: Una visión regional. (pp. 17-26). En: Pérez, L. (Ed.). Desarrollo rural sostenible en Costa Rica:Avances y perspectivas. San José: Editorial Porvenir-CECADE.

Weller, J. (1996). Efectos del ajuste estructural en el empleo y los ingresos agropecuarios, con énfasis en las exportaciones no tradicionales. Los casos de Costa Rica y Honduras. (pp. 195-224). En: Nuhn, H. \& Stamm, A. Apertura comercial en Centroamérica: Nuevos retos para la agricultura. San José: Editorial DEI. 